短報〔Note〕

\title{
ゲンジボタルの羽化時の性比
}

\author{
守屋節男 ${ }^{1)}+$ 山 山内健生 ${ }^{1), 2) *} \cdot$ 中越信和 ${ }^{1)}$
}

\section{Sex ratios in the Japanese firefly, Luciola cruciata (Coleoptera: Lampyridae) at emergence}

\author{
Setsuo MORIYA ${ }^{1) \dagger}$, Takeo YAMAUCHI $^{1), 2) *}$ and Nobukazu NAKAGOSHI ${ }^{1)}$
}

\begin{abstract}
The ratio of the sexes in the Japanese firefly, Luciola cruciata (Coleoptera: Lampyridae) at emergence was surveyed. In 2006 and 2007, firefly larvae in the climbing stage were collected in Kure City, Japan. These were placed in growth chambers under 24 -h dark at 17,20 , and $23^{\circ} \mathrm{C}$, and the sex of each emerged adult was then recorded. The sex ratios of emerged adults under three temperature conditions were significantly male-biased in both years, but were not significantly different among the three temperature conditions in each year.
\end{abstract}

Key words: emerged adult, climbing larvae, temperature condition

\section{摘 要}

2006 年および 2007 年の 4-5 月に, 広島県呉市にて上陸中のゲンジボタル幼虫を採集し，17，20， $23^{\circ} \mathrm{C}$ に設定した恒温器内で全暗状態にて飼育し, 羽化成虫の性比（雄比）を調查した。その結果，羽化 時の性比は，2006 年が $60.3 \%$ ，および 2007 年が $64.7 \%$ で，両年とも有意に雄に偏っていた。また，す べての温度区で雄が有意に多く羽化し, 温度条件による性比の変動はみられなかった。

キーワード : 羽化成虫, 上陸幼虫, 飼育温度

（2008 年 8 月 21 日受付； 2008 年 11 月 21 日受理）

\section{はじめに}

ゲンジボタル Luciola cruciata Motschulsky（コウチュ ウ目：ホタル科）は，日本の固有種で，ホタル科の 中で幼虫が水中生活を行なら数少ない種のひとつであ る。その幼虫は水中で淡水生巻貝（主としてカワニナ Semisulcospira libertina libertina (Gould)）を捕食して成
長し, 春の夜に川岸へ上陸し, 土中に潜って蛹となる（神 田，1935）。本種はすべての発育段階で発光することが 知られるが, 特に上陸後の老熟幼虫と成虫はよく発光し, 夜間に観察しやすいため, その生態は比較的よく研究さ れている。しかし，本種の性比に関する知見は非常に少 ない。本種の染色体数は雌雄とも $2 \mathrm{n}=18$ で, 性決定様 式は雄へテロ XY 型である (井上・山本, 1987)。したがっ

1) 広島大学大学院国際協力研究科 $\overline{\mathbf{T}} 739-8529$ 東広島市鏡山 1-5-1 Graduate School for International Development and Cooperation, Hiroshima University, 1-5-1 Kagamiyama, Higashi-Hiroshima 739-8529, Japan

2) 現所属: 富山県衛生研究所 ⿳亠丷厂巾 939-0363 富山県射水市中太閤山 17-1 Present address: Toyama Institute of Health, 17-1 Nakataikoyama, Imizu, Toyama 939-0363, Japan

"故人（2007 年 11 月 30 日逝去; Deceased, November 30, 2007)

*連絡先 (Corresponding author) 
て, 性染色体による性決定様式に従うならば, 本種の理 論上の一次性比（受精時の性比）はす： ＝1：1 とな る。しかしながら, 京都市清滝川における標識再捕法に よって推定された 1 シーズン全体の成虫の性比（堀ら, 1978），および同地において肥満度に基づいて性別が推 定された上陸幼虫の 3 シーズン全体の性比 (Yuma, 1981) は, どちらもす： 우 $3: 1$ である。よって, 羽化直後 の成虫の性比も雄に偏っているものと予想されるが, 飼 育実験に基づいた本種の羽化時の性比に関する報告はな い。羽化直後の性比は，本種の繁殖戦略に大きく関わる 要素であり, 本種の保全活動にも資する重要な情報であ る。また，同じコウチュウ目のカミキリムシ科マツノマ ダラカミキリ Monochamus alternatus Hope では，幼虫期 以降の温度条件によって羽化脱出した成虫の性比が変動 することが示唆されており（岸，1988）, 夏季の気温が 異常な高温になると羽化脱出個体に占める雌の比率が小 さくなる事例が示されている（谷脇ら，2003)。ゲンジ ボタルについては温度条件と性比の関係が不明であるた め, 本研究では, 上陸幼虫を 3 つ温度条件で飼育し, 羽化時の性比を調べた。

\section{材料と方法}

\section{調査地の概要}

上陸幼虫の捕獲は, Moriya et al. (2007) と同じく,
広島県呉市を流れる二河川（総延長 $21 \mathrm{~km} ）$ の支流であ る鎌ヶ原川で行なった。捕獲地は，標高 $220 \mathrm{~m}$ で，川幅 $2 \mathrm{~m}$, 両岸は高さ $2 \mathrm{~m}$ のコンクリート護岸, 川底には大 小の石があり, 毎年ゲンジボタルの成虫が飛翔する場所 である。

\section{調査方法}

ゲンジボタル上陸幼虫の捕獲は, 2006 年の 4 月 4 日 から 5 月 6 日にかけて 7 回, および 2007 年の 4 月 13 日 から 5 月 16 日にかけて 7 回実施した (Table 1)。その際, 幼虫の発光を目印として，上陸中の幼虫をランダムに捕 獲した。なお，これらの捕獲日は，この地域における幼 虫上陸期間のほぼ全体に該当する（守屋ら，2006）。

捕獲した幼虫を，Yuma（1981）の方法を参考に，円 筒形の蛹化用飼育容器（直径 $3.1 \mathrm{~cm}$, 高さ $5.1 \mathrm{~cm}$ ）に 1 頭ずつ投入した。これらの容器を, 幼虫の重量に偏り が生じないよう3つのグループに分け，それぞれ 17, $20,23^{\circ} \mathrm{C}$ 設定した恒温器（2台の Incubator SANYOMIR252 と 1 台の HITACHI-CRB32A, 温度分布精度士 $1.0^{\circ} \mathrm{C}$ ）内で全暗状態にて飼育した（Table 1)。供試虫の 羽化を毎朝確認し，それらの性別を記録した。

\section{統計解析}

性比の解析には $\chi^{2}$ 検定を用いた。

Table 1. Incubation conditions and sample information (numbers) of climbing larvae of Luciola cruciata used in rearing experiments.

表 1. 上陸幼虫の採集日と実験に用いた個体数.

\begin{tabular}{cccccc}
\hline \hline \multirow{3}{*}{ Year } & Sampling & \multicolumn{3}{c}{ Incubation conditions } & Total \\
\cline { 2 - 5 } & Date & $17^{\circ} \mathrm{C}$ & $20^{\circ} \mathrm{C}$ & $23^{\circ} \mathrm{C}$ & \\
\hline \multirow{5}{*}{2006} & Apr. 4 & 25 & 25 & 24 & 74 \\
& Apr. 10 & 25 & 26 & 26 & 77 \\
& Apr. 15 & 27 & 26 & 26 & 79 \\
& Apr. 19 & 27 & 28 & 28 & 83 \\
& Apr. 22 & 28 & 28 & 28 & 84 \\
& Apr. 26 & 22 & 22 & 23 & 67 \\
& May 6 & 26 & 26 & 27 & 79 \\
\cline { 2 - 5 } & Total & 180 & 181 & 182 & 543 \\
\hline \multirow{5}{*}{2007} & Apr. 13 & 99 & 99 & 99 & 297 \\
& Apr. 16 & 50 & 50 & 49 & 149 \\
& Apr. 18 & 37 & 37 & 37 & 111 \\
& Apr. 22 & 62 & 61 & 61 & 184 \\
& Apr. 30 & 16 & 17 & 17 & 50 \\
& May 5 & 34 & 33 & 33 & 100 \\
& May 16 & 21 & 20 & 20 & 61 \\
\hline & Total & 319 & 317 & 316 & 952 \\
\hline
\end{tabular}




\section{ゲンジボタルの羽化時の性比}

Table 2. Sex ratios (male \%) of emerged Luciola cruciata at each incubation condition (17, 20 and $23^{\circ} \mathrm{C}$ ).

表 2. 上陸幼虫の採集日と飼育温度別の性比（雄比）.

\begin{tabular}{|c|c|c|c|c|c|}
\hline \multirow{2}{*}{ Year } & \multirow{2}{*}{$\begin{array}{c}\text { Sampling } \\
\text { Date }\end{array}$} & \multicolumn{3}{|c|}{ Incubation conditions } & \multirow[t]{2}{*}{ Total } \\
\hline & & $17^{\circ} \mathrm{C}$ & $20^{\circ} \mathrm{C}$ & $23^{\circ} \mathrm{C}$ & \\
\hline \multirow{8}{*}{2006} & Apr. 4 & $69.6(23)$ & $66.7(24)$ & $68.4(19)$ & $68.2(66) * *$ \\
\hline & Apr. 10 & $61.9(21)$ & $50.0(22)$ & $33.3(18)$ & $49.2(61)^{\text {n.s. }}$ \\
\hline & Apr. 15 & $58.3(24)$ & $55.0(20)$ & $66.7(18)$ & $59.7(62)^{\text {n.s. }}$ \\
\hline & Apr. 19 & $64.0(25)$ & $68.0(25)$ & $77.3(22)$ & $69.4(72) * *$ \\
\hline & Apr. 22 & $51.9(27)$ & $55.6(27)$ & $63.6(22)$ & $56.6(76)^{\text {n.s. }}$ \\
\hline & Apr. 26 & $57.1(21)$ & $64.3(14)$ & $68.8(16)$ & $62.7(51) *$ \\
\hline & May 6 & $54.5(22)$ & $55.6(18)$ & $55.6(18)$ & $55.2(58)^{\text {n.s. }}$ \\
\hline & Total & $59.5(163) *$ & $59.3(150) *$ & $62.4(133) * *$ & $60.3(446) * *$ \\
\hline \multirow{8}{*}{2007} & Apr. 13 & $68.8(77)$ & $60.9(46)$ & $67.2(58)$ & $66.3(181) * *$ \\
\hline & Apr. 16 & $67.6(34)$ & $66.7(39)$ & $65.5(29)$ & $66.7(102) * *$ \\
\hline & Apr. 18 & $74.1(27)$ & $76.0(25)$ & $59.1(22)$ & $70.3(74) * *$ \\
\hline & Apr. 22 & $68.9(45)$ & $51.2(43)$ & 78.9 (19) & $63.6(107) * *$ \\
\hline & Apr. 30 & $54.5(11)$ & $66.7(6)$ & $37.5(8)$ & $52.0(25)^{\text {n.s. }}$ \\
\hline & May 5 & $53.3(15)$ & $41.7(12)$ & $57.1(7)$ & $50.0(34)^{\text {n.s. }}$ \\
\hline & May 16 & $100.0(3)$ & $50.0(4)$ & $66.7(6)$ & $69.2(13)^{\text {n.s. }}$ \\
\hline & Total & $67.9(212) * *$ & $60.6(175) * *$ & $65.1(149) * *$ & $64.7(536) * *$ \\
\hline
\end{tabular}

Numbers in parentheses indicate total numbers emerged.

Asterisks $(* P<0.05, * * P<0.01)$ present a significant difference from the expected value when sex ratio was thought to be 1:1 by chi-square test. ${ }^{\text {n.s. }}$ Not significant.

\section{結果}

2006 年に捕獲した上陸幼虫 543 頭のうち, 羽化した のは 446 頭（羽化率 $82.1 \%$ ）で，その性比は有意に雄 に偏っていた（の： + $=269: 177, \chi^{2}=18.97758, P<$ 0.001)（Table 2)。

2007 年に捕獲した上陸幼虫 952 頭のらち, 羽化した のは 536 頭（羽化率 $56.3 \%$ ）で，その性比は有意に雄 に偏っていた（ð： + $=347: 189, \chi^{2}=46.57462, P<$ 0.001) (Table 2)。

上陸時期と性比の関係については，2006 年には明確 な傾向はみられなかったが，2007 年には期間の前半で 有意に雄が多い傾向がみられた（Table 2)。

温度条件と性比の関係については，いずれの年に おいても, すべての温度区で有意に雄が多く（雄比 59.3-67.9\%)，また温度条件による性比の変動に有意差 はなかった（Kruskal-Wallis 検定， $P>0.05$, Table 2)。

\section{考察}

羽化成虫の性比はいずれの年においても有意に雄へ 偏っていた。この結果は, 羽化成虫の性比は雄に偏ると いう堀ら（1978）の推定を支持するものである。一方, 本研究では飼育途中（前蛹〜蛹期間中）に死亡した個体
数が多かったため, 上陸幼虫の正確な性比を求めること はできない。したがって, 上陸幼虫の性比が雄に偏ると いう Yuma（1981）の推定に関してはここで議論するこ とができない。

ゲンジボタルの性決定は XX-XY（雄へテロ）型の性 染色体に支配されるので, 理論上, 受精時の性比はす： 早 $=1: 1$ となる。したがって, 本研究の結果は, 受精 から羽化までの間に性比が雄に偏ったことを示してい る。なお, 蛹の時期の生存率には雌雄で差がないとの 報告（遊磨, 1982）があることから, 受精から蛹化まで の期間における雌の死亡率が高いものと考えられる。蛹 化までの期間における死亡要因については不明な点も多 いが，病気や環境変化に対する而性に性差があり，雌雄 の死亡率が異なっている可能性がある。また, 幼虫期 における捕食されやすさに雌雄差が存在する可能性も ある。ゲンジボタルの幼虫は成虫と同様に捕食者に対 する忌避物質をもつとされるが（神田，1935; 南，1961; 大場, 1988; 東京ゲンジボタル研究所, 2004), アメリ カザリガニ Procambarus clarkii (Girard), ミヤマアカネ Sympetrum pedemontanum elatum (Selys) の幼虫, ウスバ キトンボ Pantala flavescens (Fabricius) の幼虫, アブラ ボテ Tanakia limbata (Temminck and Schlegel), カワムツ Zacco temminckii (Temminck and Schlegel) がゲンジボタ ルの 1 齢幼虫を捕食することが実験的に確認されている 
ことから（守屋, 2001), 幼虫期の死亡要因として捕食 者による影響が大きいことも考えられる。また，ゲンジ ボタル幼虫の上陸時期には, 雄よりも雌の方が大型であ るため (Yuma, 1981; Moriya et al., 2007), 捕食者に発見 さる確率も雌の方が高いという可能性をあげることがで きる。それに関連して, より大型となる雌幼虫の方が雄 幼虫よりも多くの餌を必要とし, 餌となる淡水生巻貝を 求めて移動する頻度が高いため, 捕食者に発見されやす いといらことも考えられる。しかし, ゲンジボタル幼虫 の行動に雌雄差があるか否かはこれまで調べられたこと がなく, 蛹化までの死亡率における雌雄差とともに今後 の研究課題である。

本研究で示された羽化時の雄比は, 2006 年が $60.3 \%$, および 2007 年が $64.7 \%$ で, 両年とも堀ら（1978）が標 識再捕法を基に推定した成虫の雄比 $75 \%$ よりも低かっ た。堀ら（1978）と本研究における性比の違いは, 推定 值と実測值の違いなのかもしれないが, 調查地や調査年 の違いによるものとも考えられる。ゲンジボタルの他の 地域個体群においても性比に関する研究が実施されるこ とが望まれる。

他のホタル科昆虫で知られているように（Lewis and Wang, 1991 など)，ゲンジボタルにおいても成虫羽化期 の前期には雄比が高く, 発生期が進むにつれて雌比が高 くなることが報告されている（堀ら，1978; 守屋, 2004）。 本研究のうち， 2007 年のみではあるが調査期間前半に 有意に雄が多く羽化したことは，こうした現象と一致す る。

温度条件によっては雌雄いずれかの死亡率が高くな り, 性比が変動する可能性もあると考えられるが, 本実 験で設定した $17-23^{\circ} \mathrm{C}$ 範囲では, 全温度区で羽化成虫 の雄比が有意に高く, 温度区間で性比の有意な変動はみ られなかった（Table 2)。したがって，この温度範囲で は, 老熟幼虫から羽化までの死亡率に雌雄差はないこと が示唆された。

\section{謝辞}

本研究を遂行するにあたって, 調査に協力いただいた 「ひろしま自然の会」の守屋泰祐氏, 資料作成を手伝っ ていただいた吳市水道局の福島彰宏氏, データ解析の アドバイスをいただいた吳大学の丸井美保教授に深く感 謝申し上げる。さらに，原稿の校閲をしていただき，多 数の有益なご助言をいただいた農業・食品産業技術総合 研究機構果樹研究所の井上広光博士に厚くお礼申し上げ
る。本研究成果を発表するにあたって, 山口大学の守屋 康子氏にひとかどならぬご尽力をいただいた。心からの お礼を申し上げる。

\section{文献}

堀 道雄 - 遊磨正秀 -上田哲行 - 遠藤 彰 - 伴 浩治 村上興正 (1978): ゲンジボタル成虫の野外個体群．イ ンセクタリゥム, 15(6): 4-11.

井上正志・山本秀行 (1987): ホタル科の細胞学的研究

I. ヘイケボタルとゲンジボタルの核型。染色体 . 2, 45: 1440-1443.

神田左京 (1935): ホタル. 日本発光生物研究会（復刻版 1981）, サイエンティスト社, 東京.

岸 洋一 (1988): マツ材線虫病一松くい虫一精説 . トー マスカンパニー, 東京.

Lewis, S. M. and Wang, O. T. (1991): Reproductive ecology of two species of Photinus fireflies (Coleoptera: Lampyridae). Psyche, 98: 293-307.

南 喜一郎 (1961): ホタルの研究. 太田書店（復刻版 1983）, サイエンティスト社,東京.

守屋節男 (2001): ゲンジボタル幼虫の捕食者に関する実 験. 全国ホタル研究会誌, (34): 31-34.

守屋節男 (2004): 広島県吳市におけるゲンジボタルの調 查·研究. 全国ホタル研究会誌, (37): 38-43.

守屋節男 ・ 山内健生 ・ 中越信和 (2006): 広島県吳市にお けるゲンジボタル幼虫の上陸行動. 昆蟲 (ニューシリー ズ) , 9: 59-68.

Moriya, S., Yamauchi, T. and Nakagoshi, N. (2007): Weight of the climbing larva of the firefly Luciola cruciata (Coleoptera: Lampyridae) and its relationship to size, weight, and sex of the adult. Entomological Review of Japan, 62: 127-134.

大場信義 (1988): ゲンジボタル. 文一総合出版, 東京.

谷脇 徹・興津真行・細田浩司・阿部 豊 (2003): 異な る環境下のマツ丸太から羽化脱出したマツノマダラカ ミキリの消長と性比.フィールドサイエンス , 3: 25-30. 東京ゲンジボタル研究所 (2004): ホタル百科. 丸善株式 会社, 東京.

Yuma, M. (1981): The body size variation of the climbing larvae of the firefly, Luciola cruciata (Coleoptera; Lampyridae). Japanese Journal of Ecology, 31: 57-66.

遊磨正秀 (1982): ゲンジボタルの上陸幼虫. インセクタ リウム 19(5): 14-22. 